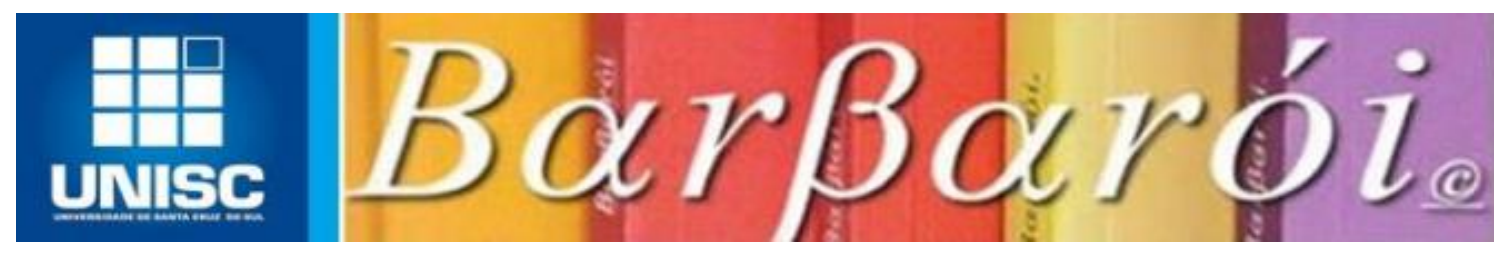

\title{
ENIGMAS DE UM FEMININO ENCARCERADO E SEUS PRINCÍPIOS DE SEGREGAÇÃO
}

\author{
DOI: http://dx.doi.org/10.17058/barbaroi.v2i52.11739 \\ Luma de Oliveira \\ Universidade Federal de Uberlândia - UFU - Brasil \\ Anamaria Silva Neves \\ Universidade Federal de Uberlândia - UFU - Brasil \\ João Luiz Leitão Paravidini \\ Universidade Federal de Uberlândia - UFU - Brasil
}

\section{RESUMO}

As falhas do sistema carcerário no Brasil não são surpresas para a população e estão cada vez mais em evidência. Apesar de afetar sujeitos de todos os gêneros, este artigo propõe uma reflexão teórica sobre efeitos do fenômeno de encarceramento especificamente sobre mulheres e, em especial, que tenham cometido algum delito relacionado a drogas. Ao se deparar com alarmantes dados sobre o tema, o interesse por tal reflexão exacerbou-se ao considerar-se a indissociabilidade dos contextos psicossocial e político para pensar diferentes modalidades de segregação existentes nas relações humanas. Para a reflexão proposta, recorreu-se a teorias psicanalíticas sobre a condição feminina, a considerações sobre o surgimento da prisão pela perspectiva foucaltiana e à análise de documentos como um "Guia para a reforma em políticas na América Latina e no Caribe" e documentários brasileiros sobre encarceramento feminino, articulando revisão de literatura, pesquisa documental e recursos artísticos a uma pesquisa exploratória. Como resultado, convidou-se os leitores a pensar em alternativas às políticas carcerária e de drogas vigentes atualmente no país e atentaremse às questões de gênero, trazendo posicionamentos dos autores e propostas que já circulam em grupos de trabalhos a respeito da temática. As propostas vão no intuito de tentar proporcionar maiores espaços de escuta e se trabalhar com "um a um", como a prática psicanalítica convida e a condição feminina implica.

Palavras-chave: Encarceramento feminino; dependência química; segregação; políticas de drogas

"Ela é tão livre que um dia será presa. Presa por quê? Por excesso de liberdade. Mas essa liberdade é inocente? É. Até mesmo ingênua. Então por que a prisão? Porque a liberdade ofende. " (Clarice Lispector - Um Sopro de Vida (Pulsações)). 
Apesar da divisão entre ser homem ou mulher ir além de proposições anatômicas relacionadas a ter ou não um pênis, como defendido por Grant (1998), escolhe-se aqui trabalhar com a feminilidade do lado da figura anatômica comumente designada às mulheres, ressaltando a necessidade de realizar recortes para trabalho.

Por isso, apesar da importância de se pensar nos efeitos de certos fenômenos para sujeitos de qualquer gênero, escolhe-se trabalhar com o encarceramento de mulheres que se relacionam com substâncias psicoativas pelo consumo ou por práticas ilícitas, refletindo sobre curiosos e alarmantes dados a esse respeito que possibilitam reconhecer diferentes formas de segregação que envolvem tal grupo. Ainda, a temática levantada pode suscitar reflexões sobre os ideais de liberdade em voga na sociedade contemporânea ocidental.

Para promover tal discussão, então, trabalhar-se-á com elementos psicanalíticos sobre o feminino, com dados de páginas governamentais e serão articulados ao texto um Guia para Reformas em Políticas na América Latina e no Caribe resultante de um Grupo de Trabalho sobre Mulheres, Políticas de Drogas e Encarceramento (2016), alguns elementos históricos sobre a origem da prisão conforme Foucault (1987) e alguns documentários brasileiros sobre o tema como "As mulheres e o cárcere" (2016), "O Cárcere e a Rua" (2004) e "Se eu não tivesse amor" (2010), utilizando-se da arte como aliada. Todos os recursos utilizados no texto caminham para o que demonstra ser uma urgência de discussão a respeito do problema.

\section{O feminino na Psicanálise}

Quando se pensa na mulher, não é de hoje que diferentes e enigmáticas figuras femininas são associadas e dificilmente representadas de maneira consensual, podendo lembrar-se de algumas delas como bruxas, feiticeiras, curandeiras, putas e cartomantes, por exemplo. $\mathrm{O}$ que de imediato pode-se afirmar de comum entre essas figuras é que nelas supõe-se um saber sobre algo a que os homens não têm acesso, um enigma sobre algo oculto.

Pensando pela perspectiva psicanalítica, isso nada se diferencia do proposto por autores como Freud e Lacan. Os autores trazem a impossibilidade de uma identificação conceitual da Mulher e Lacan (1985) tenta representar o feminino por meio de um "saber fazer" com um gozo particular, que se representa no não todo, o que remete à invenção/criação.

A Mulher aí escrita com maiúscula se dá no sentido de que não há um gozo que

Barbarói, Santa Cruz do Sul, n. 52, p.<91-113>, jul/dez, 2018 
atenda ao universal "mulher" e não há algo que se afirme como definição para todas as mulheres, assim como se poderia dizer de uma Verdade, que ao ser escrita em maiúscula remete a uma certeza pura para todos. Mas afirmar a impossibilidade de existência da Mulher, como propõe Lacan, não impede afirmar a existência da condição feminina (Soler, 2005).

\begin{abstract}
Neste contexto vale lembrar que usamos o significante Mulher para denominar a especificidade daquilo que está fora do significante... Como falar daquilo que não se pode falar? Esta ausência de um termo para dizer A Mulher deixa indeterminada uma identificação especificamente feminina. Ela escapa às palavras e está sempre em outro lugar que não aquele em que se diz estar. Perde a identidade e o nome, no caminho em direção ao gozo que lhe é próprio. Este gozo para além do falo, Lacan o denominou Outro gozo (Grant, 1998, p. 259).
\end{abstract}

Em 1933, em sua conferência sobre feminilidade, Freud traz esse termo sob a natureza de um enigma e demonstra não conseguir responder do lugar de uma ciência coerente e positivista, sugerindo até que se desejassem saber mais sobre a feminilidade, que buscassem outras fontes como os poetas.

No entanto, por mais que o autor não traga conceituações bem definidas, traz importantes contribuições a respeito da complexidade da condição feminina, e se faz pertinente trazer algumas delas para seguir com a reflexão proposta aqui sobre o que de tão assustador e inapreensível há nas mulheres e em grupos específicos delas, que gera como resposta imediatas tentativas de aprisionamento.

Freud (1933) aponta a importância de conhecer melhor o que envolve a fase préedípica de vinculação da menina à mãe, denotando um trabalhoso processo que deve ser elaborado psiquicamente pela menina. O autor (1933) afirma que até a fase fálica (fase de desenvolvimento pré-edípica) não há uma diferenciação entre a sexualidade feminina e a masculina, mas após o Édipo, há dois trabalhos para as meninas: o da adolescência e um outro, o da feminilização. O trabalho da adolescência é parecido com o dos meninos, inventar uma resposta ao sexo. Já em relação a tornar-se mulher, as meninas necessitam realizar uma mudança de zona erógena e de objeto de amor, bem como uma mudança de posição ativa para passiva.

Diante desses impasses que já estavam em discussão pelo autor, Freud (1931) indica três caminhos evolutivos possíveis para as mulheres: o afastamento da sexualidade, a autoafirmação da masculinidade e a feminilidade normal. O último é resultado de um processo no qual a castração surge como condição necessária. 
A menina que na relação pré-edípica assume posição de falo (objeto de desejo) para a figura materna, como o menino, deve desprender-se da mãe e tomar o pai como objeto de amor. Esta mudança de objeto, da mãe para o pai, implica então em deixar de ser o falo materno para não ter o falo, "caminho por excelência para a feminilidade" (GRANT, 1998, p.249).

Mas nessa busca por uma representação que desse conta da feminilidade, Freud (1931) deparou-se com características masculinas que continuavam ativas na vida da mulher adulta normal, e diante do impasse o autor (1931) responde que ser mulher é ser mãe. No entanto, cada vez mais mulheres optam por não serem mães e não se pode dizer que elas não sejam femininas.

Outra teoria sobre a feminilidade é a da mascarada, que apesar de aparecer em vários autores, ficou mais conhecida como sendo atribuída à Joan Riviere. Uma das formas de se interpretar tal teoria é pensar que o lugar de representação do feminino é do vazio e para isso as mulheres recorrem ao artifício de uma máscara no sentido de fazer velar a angústia "se fazendo" de falo para o homem, em uma lógica idealizada de complementariedade. Trata-se de um recurso como máscara por parecer deixar de lado uma parcela essencial da feminilidade para se fazer de falo.

Na perspectiva de Riviere (1929), a feminilidade é a própria máscara usada em forma de sedução e subserviência pela mulher como um disfarce para ocultar sua posse da masculinidade e evitar uma vingança masculina por isso. Nessa mulher a forte necessidade de reconhecimento por seus feitos pode se dar como uma necessidade de absolvição. Isso parece ir ao encontro daquelas atribuições femininas enigmáticas mencionadas no início do texto, já que essa forma de constituição traz a fantasia sobre um perigo oculto inerente à mulher.

Ao pensar numa psicanálise extramuros, como proposto por Laplanche (1992), considerando essas teorias sobre o feminino e a investigação de fenômenos sociais desde Freud, fica evidente o convite psicanalítico a pensar que há diferenças fundamentais que marcam a condição constituinte das mulheres e isso é ainda reforçado quando se leva em consideração os papeis historicamente designados a elas, que se diferenciam dos papeis masculinos.

Laplanche (1992) propõe a denominação de "psicanálise extramuros" para a psicanálise em operação fora do contexto de tratamento no setting de uma sala fechada. Essa noção remete à ideia do desenvolvimento de uma teoria e metodologia construídas num campo privilegiado (do setting de tratamento) a serem transferidas para outros 
campos e o autor destaca que importantes textos para o desenvolvimento da psicanálise são extramuros, não sendo secundários em Freud.

\section{Concepções sobre a relação sujeito-droga e seus efeitos}

Para contextualização dessa discussão que extrapola o setting de tratamento analítico, traz-se o conceito de "drogas" conforme a legislação do país. A lei no 11.343/2006, que institui o Sistema Nacional de Políticas Públicas sobre Drogas (Sisnad), prescreve medidas para prevenção de uso indevido, atenção e reinserção social de usuários e dependentes de drogas, estabelece normas para repressão à produção não autorizada e ao tráfico de drogas, define crimes e dá outras providências (Presidência da República, 2006). Por esta lei, consideram-se como drogas as substâncias capazes de causar dependência física ou psíquica, especificadas em lei ou relacionadas em listas atualizadas pelo Poder Executivo da União.

Essas substâncias costumam ser culturalmente chamadas de "drogas", mas as nomenclaturas variam entre "substâncias tóxicas", "substâncias psicoativas" (SPA), "tóxicos", etc., refletindo em consequente dificuldade para designar sujeitos que fazem um consumo problemático dessas substâncias e havendo na bibliografia diferentes termos para referência a eles: adictos, toxicômanos, dependentes químicos, farmacodepentes, entre outros.

No entanto, esses termos parecem colocar o caráter problemático exclusivamente na substância, desconsiderando as variadas formas de subjetivação em relação a esse objeto de satisfação. E assim como para Le Poulichet (1990), a defesa realizada aqui é de que o tóxico não é a droga, e sim a relação do sujeito com essa substância e que lugar ela ocupa na relação do sujeito com o outro.

Considerando a escolha psicanalítica como método de investigação e operador das reflexões desse trabalho, ressalta-se que para além de qualquer nomenclatura, o que se faz mais importante é o próprio sujeito do inconsciente, que se revela um a um. Assim, acredita-se que nenhum desses termos atende integralmente a complexidade do que envolve essa relação sujeito-substância-outro, mas pela facilidade que pode ser dada à compreensão do texto e pelo entendimento comum sobre os nomes, ao longo do artigo serão usados alguns dos termos, porém não caracterizando nenhuma preferência.

Dito isto, acredita-se ser pertinente uma breve consideração sobre a percepção social da droga e do usuário dela. Um usuário dependente da droga revela 
paradoxalmente o que há de mais insuportável na condição humana: revela a sujeira, a degradação e a possibilidade de satisfação por um gozo excludente, que reduz o outro a um nada. Entende-se aqui o gozo no sentido de uma tentativa inconsciente de recuperação de prazer ante o sofrimento, podendo ter como resultado o retorno da própria insatisfação. Em função dessa forma particular de funcionamento, o sujeito acaba transformando a sua possibilidade de laço com o outro em um laço com o objeto droga.

Em geral, esse sujeito escancara o desamparo humano e a incompletude por meio da repetição da busca pelo que parece ser a maior satisfação conseguida. Essa condição por vezes dispensa a inscrição do sujeito na linguagem, podendo movimentarse e satisfazer-se por um corpo que fala, demanda, deseja, sente e repete. Assim, não é preciso que o sujeito diga para onde seu desejo se direciona ou tente obtê-lo por meio da relação com o outro.

A relação do sujeito com a droga no âmbito da dependência trata-se de uma revelação social paradoxal à medida que parece atender as exigências vigentes de consumo, de busca por independência e de liberdade das relações humanas e ao mesmo tempo se mostra fora de uma lógica de produção e de normas tidas como comum a todos.

Ribeiro (2003) traz a gênese do ideal moderno de liberdade apontando uma diferenciação básica entre a concepção desse fenômeno para os gregos antigos e para os modernos. Para os antigos, a liberdade envolvia a partilha do poder social de forma igualitária entre todos os cidadãos de uma mesma pátria. Já para os modernos, a liberdade está mais relacionada a poder fazer as coisas conforme a vontade de cada um, se aproximando aí do individualismo que funda a chamada cultura do narcisismo na sociedade contemporânea.

A dependência química pode ser entendida como uma tentativa de realizar este ideal narcísico de autossuficiência, excluindo o outro como parceiro possível de gozo. Afinal, reconhecer que o objeto de nosso desejo é outro desejo, ou o desejo do Outro, seria a própria negação da liberdade. Mas o toxicômano escancara o fracasso desse modo de funcionamento, já que nessa tentativa de dominar o objeto do desejo, a independência acaba sempre sendo efêmera, sucedendo-a alguma forma de dependência (Ribeiro, 2003).

Outro fator que reforça o fracasso dessa tentativa de independência total das relações, é que

Barbarói, Santa Cruz do Sul, n. 52, p.<91-113>, jul/dez, 2018 
se existe algo que garanta a coesão social, algo que possa ser chamado de "laço fundamental", este algo são as relações de dependência enquanto expressões de uma reciprocidade permanente, e necessária, para a maioria dos membros de um grupo. Trata-se, portanto, de uma dependência estrutural e estruturante em relação ao Outro (universo simbólico) e aos outros (com os quais estabelecemos nossas trocas). (RIBEIRO, 2003, p. 14).

Assim, se o sujeito se funda na relação de dependência, pensar na total independência dos laços pode ser desesperador. Diante deste misto de dependência e independência, pode-se afirmar que o ideal de liberdade tido pela maioria, impõe ao sujeito uma árdua tarefa, a de ser livre e ao mesmo tempo se fazer valer socialmente. Ou seja, ser independente, mas buscar reconhecimento social que testemunhe seu valor, mostrando que levar a sério a concepção de que viver conforme a própria vontade em detrimento das normas sociais, é uma tentativa ingênua de liberdade e não sem consequências.

Já em "O mal-estar na civilização", Freud (1930) traz esse paradoxo de liberdade quando retrata o sofrimento e o sentimento de culpa que permeiam a necessidade de ajustamento do sujeito às relações com os outros na sociedade e na constituição da cultura. Não sabendo como satisfazer as demandas pulsionais sem entrar em conflito com a moral e a repressão social, o sujeito se vê coagido, não podendo gozar como se quer com os objetos que lhe satisfazem.

Como o toxicômano revela essa dupla faceta social do que se quer e do que se abomina, fica clara a dificuldade de dar um lugar a esse sujeito e historicamente o que se tem oferecido é o lugar de segregação, carregado por concepções moralistas incentivadas pela religião e pela mídia.

Macrae e Simões (2000) chamam a atenção para a contribuição da imprensa a partir dos anos 50, que enfatizava um “desvio de caráter" como característica atribuída a pessoas usuárias de maconha, por exemplo. Os autores (2000) dizem que a mídia teve mais influência que as pesquisas científicas da época ao instruir como as novas gerações deveriam se comportar sobre o assunto, marcando um distanciamento desses sujeitos e a redução de quem tem problemas decorrentes do uso de alguma substância a "bêbados", “drogados", "noiados", "vagabundos", etc., impedindo que para além desses papeis, eles pudessem ocupar os de homens, mulheres, pais, mães, trabalhadores, entre tantos outros.

Aproveitando a reflexão dessas questões, especificamente em relação ao público feminino, de acordo com o Relatório do Observatório Europeu da Droga e da 
Toxicodependência - OEDT (2000), a utilização de drogas é vista como incompatível com o papel da mulher e a maternidade é um elemento fundamental para essa percepção. Sobre isso, as mulheres receiam ser consideradas inaptas como mães e temem perder os filhos caso decidam submeter-se a um tratamento. Estes dados significam, de acordo com o OEDT (2000), que as mulheres consumidoras de drogas enfrentam maiores dificuldades do que os homens no acesso a um tratamento adequado às suas necessidades.

Pelo que tem se acompanhado na prática clínica, enxerga-se a anulação de si (e da função materna) sendo reforçada por órgãos como o judiciário que, repetidas vezes, ressaltam que para a aptidão a ser mãe ou qualquer outra coisa é necessário que estas mulheres estejam em tratamento. Caso contrário, pode-se recorrer ao isolamento dos filhos e encarceramento como solução. E, mais que isso, intima-se que a mulher dependente química interrompa de vez e o quanto antes o uso de substâncias.

No entanto, do que se entende de tratamentos para esse fenômeno em unidades que compõem a rede de saúde do SUS, como nos Centros de Atenção Psicossocial álcool e outras drogas (CAPS AD), principalmente, há relevante consideração das dimensões subjetiva e social que constituem os sujeitos e uma tentativa de fortalecimento de autonomia dos que recorrem a essas unidades, não havendo uma fórmula que atenda a todos e podendo acontecer até de os sujeitos não interromperem o uso da substância.

Do que se acompanha da prática, entende-se que nem todos os sujeitos se dispõem a uma ressignificação de sua relação com a droga, ou pelo menos não de forma tão imediata, e muitos fatores contribuem para isso.

Como corroborado por um Guia para reformas em políticas na América Latina e no Caribe (2016), no caso das mulheres, essa dificuldade pode ocorrer por questões sociais, por influência de parceiros amorosos, por frequente sentimento de solidão, por dificuldade em lidar com a maternidade e com mudanças corporais, desafios da gravidez, vivência de violência e pouco suporte social para acolher dificuldades emocionais ligadas a esses e outros fatores, que as fazem buscar na droga a parceria (mesmo que também faltosa) que não encontram nesses outros espaços. 
Se mesmo com a oferta de tratamento nem todos querem ou conseguem se distanciar do uso ou de atitudes problemáticas em relação à droga, é pertinente a reflexão sobre o que resta a esses sujeitos, e principalmente às mulheres envolvidas nesses conflitos, levando em consideração fatores sociais, educacionais e de saúde pública. Muitas vezes a continuidade do uso de substâncias (ilícitas principalmente) e da inserção no crime faz com que elas só recebam como alternativa o encarceramento.

Conforme dados do Departamento Penitenciário Nacional (DEPEN, 2014), entre 2000 e 2014 ocorreu um aumento do encarceramento de mulheres de 567,4\%, enquanto o aumento do encarceramento masculino foi de $220,4 \%$, havendo uma curva ascendente do encarceramento em massa de mulheres e com alta representatividade de crimes relacionados a drogas.

De acordo com Lima (2015), entre 2003 e 2004, em uma análise da situação do encarceramento feminino na América Latina, crimes relacionados a drogas representavam 46\% dos casos em El Salvador, 86\% na Nicarágua, 64\% na Costa Rica, e mais de $70 \%$ na Venezuela. No Brasil, em 2012 as prisões por tráfico e envolvimento com drogas representavam 22,6\% dos homens e 64,7\% das mulheres, tendo aumentado 5 vezes em São Paulo em análises que ocorreram entre 2006 e 2012.

Esses dados chamam atenção e parecem reflexo de uma política punitiva sobre drogas na maior parte da América Latina, urgindo ser discutidos. A política de drogas vigente, com foco no proibicionismo, tende a fortalecer práticas de criminalização e penalizar crimes pouco ofensivos, já que algumas leis não distinguem claramente os diferentes níveis de envolvimento com a droga e o tráfico, sujeitando diferentes condutas a penas semelhantes.

De acordo com o Guia para reformas em políticas na América Latina e no Caribe, resultante de um Grupo de Trabalho sobre Mulheres, Políticas de Drogas e Encarceramento por membros da Advocacy for Human Rights in the Americas (WOLA), do International Drug Policy Consortium (IDPC), do Dejusticia - Derecho, Justicia, Sociedad, da Comissão Interamericana de Mulheres (CIM) e da Organização dos Estados Americanos (OEA) (2016), em muitos países as punições para delitos de drogas são mais altas do que penas para atos como estupro ou homicídio.

Esse mesmo Guia provoca importantes reflexões sobre os impactos dessa política sobre as mulheres, mostrando que o uso da prisão como resposta às drogas tem afetado desproporcionalmente esse grupo. Estudos na América do Sul para formulação 
desse Guia (2016) mostram que a maioria das mulheres privadas de liberdade já vivenciaram experiências de violência ou discriminação antes do encarceramento e tanto os delitos cometidos por mulheres para obter drogas para o consumo, como as atividades ilícitas de participação na produção, na distribuição e na venda de drogas estão frequentemente relacionados à exclusão social, à pobreza e à violência de gênero. A maioria tem pouca instrução educacional e é responsável pelo cuidado de dependentes delas, como crianças, jovens, idosos ou deficientes.

Sobre a participação das mulheres no tráfico, percebe-se que as que são presas por delitos de drogas raramente constituem grande ameaça para a sociedade, já que a maioria é detida por realizar tarefas de pouca importância (apesar de alto risco), como pequenas vendas e desempenharem papel de "olheiras" e de "correios humanos" para o transporte de drogas.

Além disso, quando retiradas de cena, essas mulheres são facilmente substituídas. Assim, sua detenção não impacta significativamente na diminuição do tráfico ou em questões de segurança para a população. Ainda, quando a pena termina, essa marca como antecedente diminui a possibilidade de encontrarem emprego formal e essa condição reforça um ciclo de exclusão social e de reinserção no encarceramento (Guia para reformas em políticas na América Latina e no Caribe, 2016).

Segundo o Guia para reformas em políticas na América Latina e no Caribe (2016), na Costa Rica, em 2012, mais de 95\% das mulheres presas por introduzirem drogas em penitenciárias eram mães e únicas responsáveis pelos seus filhos. Então não é de se espantar que muitas se envolvam em atividades ilícitas relacionadas às drogas até mesmo como forma de sustentar os filhos e que a prisão delas influencie no desenvolvimento destes, bem como contribui para a entrada dessas famílias em situações de violência.

Sobre as causas que levam as mulheres a esses delitos, muitas se assemelham às que dificultam a ressignificação da relação delas com o próprio consumo de substâncias como anteriormente mencionado. Entretanto, uma que merece ser destacada é a influência dos parceiros amorosos em tais condutas e essa questão é retratada até mesmo em documentários sobre o tema.

No documentário "Se eu não tivesse tanto amor" (2010), são apresentadas mulheres que não sabem do envolvimento de seus companheiros em práticas como assalto e tráfico no início de seus relacionamentos, por exemplo, mas que quando descobrem tornam-se cúmplices e acabam usufruindo dos benefícios dessas práticas. 
Uma das mulheres entrevistadas até afirma ter dito ao companheiro que ele poderia ter lhe contado antes porque ela ficaria com ele de qualquer forma, "por amor".

De encontro a isso, em 2015 a Pastoral Carcerária Nacional lançou um documentário dividido em duas partes que articula bem com tais questões. A primeira parte se chama "Tortura e encarceramento em massa" e a segunda, que mais nos interessa no momento, chama-se "As Mulheres e o Cárcere", divulgada em 2016. Nessa segunda parte algumas penitenciárias no país são mostradas, e, em uma delas, quando as presas são questionadas sobre seus companheiros, uma agente do local responde: "Sempre foi assim, os homens abandonam. Elas que não abandonam os homens. E a maioria foi presa por causa do marido". Um entrevistador pergunta para todas as mulheres no pátio da penitenciária se essa afirmação é verdade e a maioria responde em coro: "É!".

A isso é possível acrescentar algumas questões levantadas por Santiago (2001) sobre as particularidades do toxicômano quando questiona quem seria o parceiro desse sujeito diante da adesividade libidinal que ele vive com a droga. Tendo em vista que a linha divisória entre a inserção no tráfico e o uso contínuo de drogas é tênue e envolve questões que se entrelaçam, abre-se a questão sobre quem seriam os parceiros dessas mulheres. Se essa parceria amorosa é capenga e faltosa, em nada se difere dos seus encontros com a droga e com o crime.

Dito isso, parece surgir uma condição de abandono e solidão que figuram na mulher encarcerada e parecem muito atender a alguns interesses sociais. Se a proposta de encarceramento é divulgada em alguns momentos como forma de recuperar sujeitos e prepará-los para ressocialização, vale refletir sobre a concretização desses objetivos e quais outros estariam subjacentes, considerando o histórico dessa prática de aprisionar sujeitos.

Relembrando Bleger (1984) em suas considerações sobre a Psicologia Institucional, ressalta-se que toda instituição tem objetivos manifestos ou explícitos e implícitos ou latentes, e tendo em vista o objetivo manifesto de ressocialização de sujeitos nos presídios, resta refletir sobre os implícitos.

Para situar a discussão, vale a informação de que o sistema penal do Brasil prevê três tipos de penas: regime fechado, regime semiaberto e aberto. A Lei no 7210 de 1984, Lei de Execução Penal, traz o que cada regime deve ter. No sentido de uma progressão da pena, uma pessoa condenada a regime fechado, após cumprir 1/6 da pena com boa conduta tem direito ao regime semiaberto, em que ela ainda dorme na prisão, e 
posteriormente ao aberto, em que a pessoa dorme em albergue ou se encontra em prisão domiciliar.

Com crescente visibilidade da crise no sistema carcerário no país e a evidência de condições como superlotação, alimentação precária, falta de colchão e local adequado para dormir, dentre outras a que os presos são submetidos, hipotetiza-se sobre a criação de formas de não oferecer lugar a eles e reforçar práticas de isolamento e segregação. É curioso pensar a quem interessa a manutenção dessa prática e porque ela ocorre há anos.

Essas condições, para além disso, mostram-se ainda como uma constante violação dos direitos dos sujeitos. De encontro a isso, em “As Mulheres e o Cárcere”, da Pastoral Carcerária Nacional (2016), já de início é mostrada uma mulher com marcas de machucados que conta que policiais entraram em sua casa, a xingaram, esquentaram uma algema e o cabo de um revólver em seu fogão e a marcaram no corpo, em seguida foi atingida por spray de pimenta. Isso retrata também o lugar dado à mulher que foge às expectativas sociais.

No documentário (2016) é ressaltado o quanto a execução penal de mulheres reforça nelas um sentimento de culpa ao ser aplicada com o discurso de que elas foram parar ali por não terem cumprido suas responsabilidades de mulher e de mãe adequadamente. Às vezes parece que elas estão sendo mais punidas por isso do que por terem praticado determinados delitos. E se o encarceramento é realizado para penalizar pessoas que não cumprem com a lei, encarcera-se também em descumprimento com a lei.

Em uma das penitenciárias apresentadas nesse documentário (2016) é mostrado que as presas se encontram sem água, sem descarga no vaso sanitário que utilizam e sem papel higiênico. Além disso, algumas das presas que são mães recentes de bebês às vezes se veem obrigadas a darem banhos em suas crianças nessas condições, sem falar na falta de acompanhamento pré e pós-natal para presas gestantes e mães recentes, o que contribui para disseminação de doenças entre as crianças que nascem. Uma das participantes do documentário mencionado fala que é como se o sistema não visse diferenças entre homens e mulheres. Segundo ela "o sistema carcerário foi feito por homens para homens. O sistema as trata como se a única diferença em relação aos homens fosse a menstruação", mesmo que às vezes elas não recebam absorventes.

No início de "As Mulheres e o Cárcere" (2016) consta que a tortura é um instrumento inerente ao sistema carcerário. Sobre isso, Enriquez (1991) afirma que a 
violência parece ser substancial para a vida institucional, já que exige que os sujeitos renunciem à satisfação de suas pulsões (assim como dito por Freud, 1930) e reacende combates entre os iguais, contribuindo com o desejo de transgressões. Isso favorece a proliferação de condutas autoritárias e é mais frequente à medida em que a instituição tanto se interessa por lutas de poder.

Para fomentar a discussão, escolhe-se recorrer também a Foucault (1987), que em Vigiar e Punir traça um histórico da penalização dos sujeitos considerados desviantes às normas sociais vigentes desde o regime monárquico na França e em diferentes países. O autor (1987) mostra as penas enquanto suplício e formas de coerção, meio de disciplina e aprisionamento do ser humano, revelando a face política do controle social aplicado ao direito e às sociedades.

O suplício representou uma forma de punição típica que perdurou até o fim do século XVII e começo do século XVIII predominantemente na Europa, causando sofrimento incessante e brutal aplicado aos corpos dos sujeitos penalizados e expostos a público, por meio de amputações, esquartejamentos e marcações de símbolos. Após reivindicações e reformulações da justiça penal, vão ocorrendo modificações na forma de punição e esse suplício em forma de espetáculo vai desaparecendo. Dá-se espaço a punições menos diretamente físicas, a uma arte de fazer sofrer mais sutil.

A punição vai se tornando então a parte mais velada do processo penal, deixando de ser percepção diária e entrando numa consciência abstrata. Assim, sua eficácia é atribuída à fatalidade e não mais à intensidade tão visível. "A certeza de ser punido é que deve desviar o homem do crime e não mais o abominável teatro" (Foucault, 1987, p.13).

Agora se a liberdade é tida como um bem comum e supervalorizado na sociedade, a prisão passa a ter o foco na privação dela. Há uma tentativa de instaurar um castigo igualitário na medida em que a perda da liberdade parece ter o mesmo preço para todos. No entanto, quando é feita uma análise pelo que Enriquez (1991) chamou de operador social, como por um analista ou um educador, por exemplo, esse mito da ideologia igualitária nas instituições é desmentida. Cada sujeito acaba fazendo uso em prol de interesses particulares dessa e de outras instituições, nesse caso aparecendo diferentes concepções de justiça.

Retomando a quem essa prática interessa, Foucault (1987) traz que a aceitação da prisão é uma obviedade, já que todos conhecem seus inconvenientes mas não encontram o que colocar em seu lugar. O autor (1987) ressalta o caráter de aparelho 
transformador que foi dado a essa prática na medida em que ao encarcerar, retreinar e docilizar os sujeitos, ela reproduz mecanismos encontrados no corpo social, por mais que haja diferenças no grau de intensidade das penas conforme as infrações.

Há nessa medida o princípio do isolamento, que além de ser uma pena individual, é individualizante. A solidão acaba sendo vista como um instrumento positivo de reforma.

Jogado na solidão o condenado reflete. Colocado a sós em presença de seu crime, ele aprende a odiá-lo, e se sua alma ainda não estiver empedernida pelo mal é no isolamento que o remorso virá assalta-lo. (FOUCAULT, 1987, n.p.)

No entanto, a prática mostra o contrário. No documentário "O Cárcere e a Rua", de 2004, que retrata a realidade de mulheres presas no sistema penitenciário de Porto Alegre, uma das mulheres entrevistadas, que é apresentada como a mais antiga do local, diz que a cadeia não serviu para ela aprender nada e não vai lhe servir para o futuro porque sua vida está “desse tamanhinho" (sinalizando com as mãos um gesto de diminutivo).

Quando se isola e segrega sujeitos, enfraquece-se forças comunitárias de transformações. Isso reflete numa medida de controle desses sujeitos, garantindo que não deem nenhum passo fora do que se espera, principalmente pensando a partir da Lei e de quem a representa. A solidão é uma importante condição de submissão. Assim, é possível perceber a prática de segregação em diferentes grupos e instituições.

Sobre essa lógica, Bleger (1984) afirma que "toda instituição é o meio pelo qual os seres humanos podem se enriquecer ou empobrecer e se esvaziar como seres humanos; o que comumente se chama de adaptação é a submissão à alienação e à estereotipia institucional" (p.57).

Já entre 1912 e 1930 em Totem e Tabu e O Mal-estar na Civilização, como previamente mencionado, Freud diagnosticou o mal-estar e formas de exclusão resultantes da imersão dos sujeitos na cultura e em grupos. A partir daí, Lacan (1992) e Askofaré (2009) fazem algumas articulações sobre os fenômenos trazendo um princípio de segregação social situado em todo discurso e reforçado pela ciência moderna.

Lacan apresenta o discurso como uma forma de inserir no laço social e nas relações de poder o que ele chama de gozo, que remete à busca por satisfação pulsional que pode retornar como o fracasso dessa mesma satisfação e a uma dificuldade de 
representação simbólica. Dentre os principais discursos apontados pelo autor (1992) estão o discurso do mestre, o discurso da histérica, o discurso do analista e o discurso universitário.

Mas ao longo de sua produção, Lacan vai se interessando pelas novas formas de inserção social do homem diante do advento da ciência moderna, que implica em novas formas de subjetivação e numa racionalização total dos fatos e dos sentidos. Este fenômeno produz explicações generalizadas para as dúvidas dos sujeitos que aqui podem ser entendidos como os "sujeitos cartesianos", marcados pela experiência do pensar. Assim, essa lógica parece então excluir o que há de singular em cada um, podendo reforçar práticas segregatórias.

Soler (1998) nesse sentido traz a segregação como uma forma da civilização moderna e científica impor uma universalização de respostas aos sujeitos e de suprimir diferenças que surjam. No entanto, afirma (1998) que segregação nem sempre está associada a algo negativo, podendo ocorrer de forma voluntária por determinados grupos.

Lacan (1992), por outro lado, desconstruindo mitos freudianos sobre a figura do pai, traz que toda origem de fraternidade está fundada sobre a segregação. Segundo o autor (1992), nenhuma fraternidade "tem o menor fundamento, (...), o menor fundamento científico, se esta não for somente porque se é isolada e ao mesmo tempo, isolada do resto" (LACAN, 1992, p.132).

Freud (1913) apresenta, com o mito de Totem e Tabu, uma referência para se trabalhar a segregação. Em sua análise sobre o mito, Lacan (1992) aponta que nem a biologia, por exemplo, garante a fraternidade, já que irmãos possuem cromossomos diferentes e até opostos uns dos outros. A ordem biológica atesta a diferença dos humanos. A fraternidade, portanto, no caso do mito, não é garantida pela consanguinidade. Retomando o mito do pai da horda, segundo Askofaré (2009) é ao se reconhecerem como irmãos que podem excluir o pai e matá-lo, sendo todos filhos da morte.

Askofaré (2009) diz que o tema da segregação surge no entrecruzamento de três problemáticas, dentre elas a do laço social e o político. Assim, sobre esse princípio se inscreve a noção de segregação como efeito e como prática. Como articulado por Lacan (1992) e Soler (1998) sobre os efeitos do discurso da ciência moderna, percebe-se que na cultura contemporânea, esse discurso visa universalizar o gozo, indicando que todos têm o mesmo acesso a ele.

Barbarói, Santa Cruz do Sul, n. 52, p.〈91-113>, jul/dez, 2018 
No entanto, com o movimento de universalização, o que retorna aos sujeitos são os fenômenos da segregação. O acesso ao gozo não é universal como a ciência promete. E grande representação disso é a figura do dependente químico, que entra na lógica de consumo desenfreado, mas não produz na lógica de mercado formal como a sociedade espera. O que é dado a ele é essa resposta universalizada de "um para todos", como se a todos atendessem as mesmas propostas como as de internação ou de buscar emprego formal, por exemplo.

De acordo com o proposto até aqui, reforça-se que a segregação não é efeito, resultado ou consequência de um discurso, mas do princípio de discursos que estruturam os laços humanos, já que todas as formas de organizações humanas que se nutrem da ideia de fraternidade são tipos de arranjos em torno de um significante (como um mestre ou um líder) e segregação de outros, havendo uma forma de tratamento do gozo que só são "um devido ao outro" (Askofaré, 2009).

O discurso da ciência não concebe a segregação, mas ele e o sujeito moderno que lhe corresponde iniciam fundamentalmente uma prática da segregação. A ênfase aqui é então tanto sobre o fenômeno da segregação quanto sobre o caráter organizado, combinado e mesmo racional que esse pode ter (Askofaré, 2009).

Essa lógica desagregadora apresenta-se em instituições que se dizem de cuidados e em práticas profissionais atualmente vigentes, com pouco espaço para reflexões e para ações em direção ao singular. Exemplos disso são as práticas e os lugares destinados àqueles que exacerbam as diferenças e são identificados como loucos, criminosos, infratores, débeis e idosos, por exemplo.

No caso das mulheres, público enfatizado nesse trabalho, percebe-se de forma ainda mais gritante esses lugares de segregação ao longo da história, com trânsito entre casa, convento, fogueira para as bruxas, manicômio e por fim as prisões, que são a forma mais atual de cerceamento da liberdade e expressão de suas diferenças. Aprisiona-se não apenas o corpo, mas tudo que o permeia e a possibilidade de manifestação do diferente. Aquilo que destoa deve ser urgentemente escondido do campo de visão social.

Askofaré (2009), refletindo sobre a civilização científica vigente, traz que se a ciência é fundamentalmente conduzida pela pulsão de morte, não é de se admirar que seus efeitos não sejam de agregação, mas de segregação e mesmo de desagregação. Assim, a psicanálise, se posicionando ao lado de Eros (relações de amor), que une e agrega pelo efeito de transferência ou de massa, pode pregar peça ao projeto funesto da 
ciência gerando inovação.

\section{Considerações finais}

Há em comum entre os toxicômanos e as mulheres uma dificuldade de representação e constantes tentativas de apreendê-los principalmente pelos discursos teológico, jurídico e médico: a santa Mãe do filho de Deus, a mulher que surge da costela de Adão, a mãe exemplar que cumpre suas obrigações, a boa cozinheira que serve à família, o doente que precisa de tratamento, o sujeito com desvio de caráter, pecadores, criminosos, enfim, os sujeitos que precisam se encaixar em normas resultantes desses discursos.

No entanto, ao escolher a Psicanálise como método de investigação dessas questões que os perpassam, é impossível não reforçar a importância do olhar sobre o singular de cada sujeito. Essa posição se torna ainda mais coerente quando se percebe que o discurso da ciência, de uma resposta e uma forma de gozar proposta para todos, não dá conta do fenômeno da toxicomania e seus desdobramentos, e muito menos da condição feminina. Nesse sentido, em nada interessa à Psicanálise normatizar os sujeitos nessas situações.

Sobre isso, Enriquez (1991) afirma que os "profissionais do psíquico" são seres marginais, que não se interessam pela lógica de produção social e nem pelo poder. O autor (1991) afirma que o que caracteriza um psicanalista é o fato de em caso dele ter o poder de algo, não se utilizar desse poder e nem decidir no lugar do outro, muito menos de querer adaptar o outro diretamente ao sistema social. Segundo o autor (1991), ser marginal é se interessar por aquilo que não interessa ao sistema social: a verdade e a autonomia do sujeito.

Encerra-se então, porém não esgotando a discussão, com algumas propostas que têm sido apontadas em relação à temática investigada, inclusive algumas tendo sido mencionadas no referido Guia para Reforma em Políticas na América Latina e no Caribe (2016). Entende-se que essas propostas são tentativas de se operar com uma escuta caso a caso, além de chamar atenção para uma necessária discussão política.

É preciso a construção de uma política de drogas mais inclusiva e com garantia de direitos, com mulheres atoras nessa construção, por meio de incentivo à participação delas (especialmente as diretamente afetadas pelas políticas atuais) em debates e formulação dessas políticas; é importante criar meios e capacitar profissionais que não 
se concentrem necessariamente no judiciário para dialogar com os sujeitos e entender melhor os fatores que os levaram a cometer delitos ou realizar um uso problemático de substâncias; se faz pertinente ampliar a discussão sobre legalização de drogas e descriminalização do uso, do porte e do cultivo de drogas para consumo pessoal no país; e é fundamental desenvolver redes de apoio social e econômico que atendam sujeitos em vulnerabilidade nesses âmbitos.

Apesar de algumas mudanças, como a decisão do Supremo Tribunal Federal (STF, 2018) recentemente noticiada nas mídias de conceder prisão domiciliar a mulheres em situação de prisão preventiva gestantes e mães de crianças de até 12 anos, entende-se que ainda se tem um longo percurso a caminhar socialmente $\mathrm{e}$ legislativamente. Reforça-se a liberdade vigiada como um recurso sem violação de direitos da mulher no caso dela estar gestante, mas também a importância de se pensar em formas de acompanhamento e aproximação das mães às crianças após o nascimento, não estendendo a punição à criança.

Ressalta-se isso pois em alguns estudos e nos documentários trazidos para articulação com o artigo, é mostrado que um dos maiores sofrimentos das mulheres presas é estar gestante e ter o filho sem qualquer tipo de assistência, além de haver um superinvestimento na condição materna durante a gestação e após terem os filhos essas mulheres viverem a angústia de não saber para onde eles foram e como estão sendo cuidados. Há uma bruta ruptura dessa condição materna e dos laços familiares.

Além disso, uma sugestão na direção do cuidado é a urgente necessidade de investimento em serviços públicos de saúde como os de tratamento de dependência química em CAPS AD com pontos de apoio profissionalizantes, sociais, de saúde e de educação no território, com foco na estratégia de Redução de Danos. Entende-se que essa estratégia é uma ação política que busca construir caminhos possíveis de cuidados aos usuários de substâncias considerando as suas singularidades e ressaltando a importância de se poder contar com o suporte de equipes multiprofissionais capacitadas.

Junto a isso, é necessário um trabalho de conscientização sobre o tratamento, minimizando o quanto for possível o número de pessoas que chegam a ele de forma involuntária. Infelizmente, no entanto, ao contrário do que se propõe, o que se vê acontecendo é a diminuição de investimento nesses dispositivos, enfraquecimento deles e a injeção de dinheiro e recursos em entidades privadas.

Em síntese, o que se defende aqui é que as alternativas ao encarceramento considerem um pouco mais as necessidades humanas e suas diversidades, com redução 
das consequências negativas da privação de liberdade, deixando a prática da punição como último recurso. Como sugere o "Guia para a reforma em políticas na América Latina e no Caribe" (2016), é necessário minimizar o uso do direito penal e da pena da prisão, concentrando-se na ampliação das alternativas que evitem os impactos gerados pelo encarceramento feminino.

A finalidade das penas deveria ser o de reabilitação, ressocialização e construção de projetos de vida significativos para a mulher. Essas sugestões podem ser alternativas interessantes à afirmação encontrada em Foucault (1987) de que a prisão parece ser a “detestável solução da qual não se pode abrir mão".

\title{
THE RIDDLES OF AN INCARCERATED FEMININE AND YOUR PRINCIPLES OF SEGREGATION
}

\begin{abstract}
The failures of the prison system in Brazil are not surprises for the population and are increasingly in evidence. Although it affects people of all genders, this article proposes, however, a theoretical reflection about the effects of the phenomenon of incarceration specifically on women and in particular that have committed some crime related to drugs. When faced with alarming datas on the subject, the interest for such discussion increased considering the indissociation of the psychosocial and political contexts to think of different modes of segregation that exists in human relationships. To the proposed reflection, was used psychoanalytic theories about the female condition, considerations about the emergence of prison from the foucaultian perspective and the analysis of documents as a "Guide to reform in politics in Latin America and the Caribbean" and brazilian documentaries on female imprisonment, articulating literature review, documentary research and artistic resources to an exploratory research. As a result, readers are invited to think about alternatives to the prison and drug policies currently in force in the country and gender issues, bringing the authors' positions and proposals already circulating in working groups on the subject. The proposals are intended to try to provide greater listening space and to work with "one by one", as the psychoanalytic practice invites and how the feminine condition implies.
\end{abstract}

Keywords: Female incarceration; drug addiction; segregation; drug policies.

\section{ENIGMAS DE UM FEMENINO ENCARCELADO Y SUS PRINCIPIOS DE SEGREGACIÓN}

Resumen: Las fallas del sistema carcelario en Brasil no son sorpresas para la población y están cada vez más en evidencia. A pesar de afectar a sujetos de todos los géneros, este artículo propone una reflexión teórica sobre efectos del fenómeno de encarcelamiento específicamente sobre las mujeres y en especial que hayan cometido algún delito relacionado a las drogas. Al encontrar alarmantes datos sobre el tema, el 
interés por tal reflexión se exacerbó al considerarse la indisociación de los contextos psicosocial y político para pensar los diferentes modos de segregación existentes en las relaciones humanas. Para articular la reflexión propuesta, se recurrió a teorías psicoanalíticas sobre la condición femenina, a consideraciones sobre el surgimiento de la prisión por la perspectiva foucaltiana, análisis de documentos como un "Guía para la reforma en políticas en América Latina y el Caribe" y películas documentales brasileñas sobre encarcelamiento femenino, articulando revisión de literatura, investigación documental y recursos artísticos a una investigación exploratoria. Como resultado, se invita los lectores a pensar en alternativas a las políticas carcelarias y de drogas vigentes actualmente en el país y atentarse a cuestiones de género, trayendo posiciones de los autores y propuestas que ya circulan en grupos de trabajos acerca de la temática. Las propuestas intentan proporcionar mayores espacios de escucha y de trabajar con caso a caso, cómo la práctica psicoanalítica invita y la condición femenina implica.

Palabras clave: Encarcelamiento femenino; dependencia química; segregación; políticas de drogas.

\section{REFERÊNCIAS}

ASKOFARÉ, S. Aspectos da segregação. (1999). Tradução: Ronaldo Manzi. A peste, São Paulo, v. 1, n. 2, p. 345-354, jul./dez. 2009.

AS MULHERES e o Cárcere. Pastoral Carcerária Nacional, 2016 (19 min 04 s).

BRASIL. Presidência da República. Lei no 11.343 de 23 de Agosto de 2006. Brasília, DF. Disponível em: http://www.planalto.gov.br/ccivil_03/_ato20042006/2006/lei/111343.htm. Acesso em: 25 Set. 2017.

BRASIL. Presidência da República. Lei no 7210 de 11 de Julho 1984. Brasília, DF. Disponível em: http://www.planalto.gov.br/ccivil_03/leis/17210.htm. Acesso em: 26 Set. 2017.

BLEGER, J. Psico-Higiene e Psicologia Institucional. ARTMED. Porto Alegre, RS, 1984.

DEPARTAMENTO de Execução Penal - DEPEN. Levantamento Nacional de Informações Penitenciárias - INFOPEN MULHERES. Jun., 2014. [Online]. Disponível em: http://www.justica.gov.br/noticias/estudo-traca-perfil-da-populacao-penitenciariafeminina-no-brasil/relatorio-infopen-mulheres.pdf. Acesso em: 26 Set. 2017.

ENRIQUEZ, E. O Trabalho de Morte nas Instituições. In: A Instituição e as Instituições: Estudos Psicanalíticos. KAES, R., BLEGER, J., ENRIQUEZ, E., FORNARI. F., FUSTIER, P., ROUSSILON, R., VIDAL, J. P. São Paulo: Casa do Psicólogo, 1991, 171p.

FOUCAULT, M. Vigiar e Punir: nascimento da prisão. Tradução Raquel Ramalhete. Petrópolis, Vozes, 1987. 288p.

FREUD, S. Totem e Tabu. In: Obras Completas, Ed. Standard Brasileira. 1913. Rio de 
Janeiro: Imago, 1996.

FREUD, S. O mal-estar na civilização. In: Obras Completas, Ed. Standard Brasileira. 1930. Rio de Janeiro: Imago, Vol. XXI.

FREUD, S. Sobre a sexualidade feminina. In: Obras completas, Ed. Standard Brasileira, 1931. Rio de Janeiro: Imago, vol. XX.

FREUD, S. Conferência XXXIII. Feminilidade. In: Obras Completas, Ed. Standard Brasileira, 1933. Rio de Janeiro: Imago, vol. XXII.

GRANT, W. H. A mascarada e a feminilidade. Psicologia USP, São Paulo, v.9, n.2, 1998, pp.249-260.

LACAN. O Seminário, livro 17: O avesso da psicanálise. Rio de Janeiro: Jorge Zahar, (1969-70) 1992.

LACAN, J. O Seminário, livro 20: Mais, ainda. 2a. ed. Rio de Janeiro, Jorge Zahar, (1972-1973), 1985. Tradução de: Le Séminaire, livre XX.

LAPLANCHE, J. A psicanálise extramuros. In: Novos fundamentos para a psicanálise. São Paulo, 1992: Martins Fontes.

LE POULICHET, S. Toxicomanias y psicoanálisis: las narcosis del deseo. Buenos Aires: Amorrortu. 1990.

LIMA, R. C. Mulheres e tráfico de drogas: uma sentença tripla. Parte I. Instituto Terra, Trabalho e Cidadania (ITTC), 2015. [Online]. Disponível em:

$\mathrm{http}$ //ittc.org.br/mulheres-e-trafico-de-drogas-uma-sentenca-tripla-parte-i/. Acesso em 20 Jun. 2017.

LISPECTOR, C. Um Sopro de Vida: (Pulsações), 8a. ed. Editora Nova Fronteira, 1978.

MACRAE, E.; SIMÕES, J. A. Rodas de Fumo: uso de maconha entre as camadas médias urbanas. Salvador: Ed. Universidade Federal da Bahia, 2000.

Observatório Europeu da Droga e da Toxicodependência (OEDT). As mulheres consumidoras de drogas são mais estigmatizadas do que os homens. Comunicado da agência europeia de informação sobre droga. Relatório anual do fenómeno da droga na $U E$ - 2000. n.6, Lisboa. [Online]. Disponível em:

http://www.emcdda.europa.eu/system/files/attachments/1498/PT_pr06_ar00_women_pt .pdf. Acesso em: 20 de Jun. 2017.

O CÁRCERE e a Rua. Direção: Liliana Sulzbach. Produção: Annete Bittencourt, Everson Egas Colossi Nunes, José Pedro Goulart e Ricardo Baptista da Silva, por Zeppelin Filmes. Porto Alegre, 2004 (35 mm, 80 min).

RIBEIRO, E. M. A toxicomania e os paradoxos da liberdade. A direção da cura nas toxicomanias. Revista da Associação Psicanalítica de Porto Alegrel Associação 
Psicanalítica de Porto Alegre. - $n^{\circ}$ 24, 2003. Pp.7-17. Porto Alegre: APPOA, 1995.

RIVIERE, J. A feminilidade como máscara. International Journal of Psychoanalysis, 1929. Trad. por Ana Cecília Carvalho e Esther Carvalho. Psyche (Sao Paulo), v.9 n.16 São Paulo, dez. 2005. [Online]. Disponível em: http://pepsic.bvsalud.org/scielo.php?script=sci_arttext\&pid=S141511382005000200002 . Acesso em: 26 Jun. 2017.

SANTIAGO, J. A droga do toxicômano: uma parceria cínica na era da ciência. Rio de Janeiro: Ed. Jorge Zahar, 2001.

SE eu não tivesse amor. Direção: Geysa Chaves. Rio de Janeiro, 2010 (47 min).

SOLER, C. Sobre a segregação. In: BENTES, L.; GOMES, R. F. (Orgs.).

KALIMEROS. O Brilho da inFelicidade. Rio de Janeiro: Contra Capa, 1998.

SOLER, C. O que Lacan dizia das mulheres. Rio de Janeiro: Jorge Zahar, 2005.

SUPREMO TRIBUNAL FEDERAL. Notícias STF. $2^{a}$ Turma concede HC coletivo a gestantes e mães de filhos com até doze anos presas preventivamente. 20. Fev. 2018. [Online]. Disponível em: http://www.stf.jus.br/portal/cms/verNoticiaDetalhe.asp?idConteudo=370152. Acesso em: 27 de Fev. 2018.

YOUNGERS, C. A.; PIERES, N.; NOUGIER, M. CHAPARRO, S. Mulheres, politicas de drogas e encarceramento. Um Guia para a reforma em políticas na América Latina e no Caribe. Guia que trata da adoção, revisão e aplicação de reformas relacionadas ao encarceramento de mulheres por delitos de drogas para gestoras e gestores de políticas públicas. Grupo de Trabalho sobre Mulheres, Políticas de drogas e Encarceramento, 2016. [Online]. Disponível em: https://www.wola.org/wpcontent/uploads/2016/10/Portuguese-Report-WEB-Version.pdf. Acesso em 20 Jun. 2017.

\section{Sobre os autores}

Luma de Oliveira é psicóloga no Hospital de Clínicas de Uberlândia (HCU). Especialista em Gestão de Redes de Atenção à Saúde pela ENSP/FIOCRUZ. Mestranda em Psicologia no Instituto de Psicologia da UFU (IPUFU), linha Psicanálise e Cultura. Av. Maranhão, s/nº, Bloco 2C, Sala 2C54. Uberlândia, Minas Gerais. Endereço eletrônico: lumadeoliveira.udi@gmail.com

Anamaria Silva Neves é doutora em Psicologia pela Universidade de São Paulo (USP). Professora Associada 1 no curso de Psicologia - Graduação e Pós-Graduação Strictu Sensu - da Universidade Federal de Uberlândia (UFU). Av. Maranhão, s/no , Bloco 2C, Sala 2C54. Uberlândia, Minas Gerais. Email: anamaria.neves@ufu.br

João Luiz Leitão Paravidini é doutor em Saúde Mental pela Universidade Estadual de Campinas (UNICAMP). Professor Associado do Instituto de Psicologia na 
Universidade Federal de Uberlândia (UFU). Av. Maranhão, s/nº, Bloco 2C, Sala 2C54. Uberlândia, Minas Gerais. Email: jlparavidini@gmail.com 